\title{
Effectiveness of Counseling Based on Functional Analytic Psychotherapy with Enhanced Cognitive Therapy on the Sexual Quality of Life of Married Adolescent Women
}

\section{Eficácia do aconselhamento baseado em psicoterapia analítica funcional - Com abordagem de terapia cognitiva aprimorada (FECT) na qualidade de vida sexual de mulheres adolescentes casadas}

\author{
Maryam Gholami10 \\ ${ }^{1}$ Department of Midwifery, Razi School of Nursing and Midwifery, \\ Kerman University of Medical Sciences, Kerman, Iran \\ 2 Department of Midwifery, Nursing Research Center, Razi School of \\ Nursing and Midwifery, Kerman University of Medical Sciences, \\ Kerman, Iran \\ ${ }^{3}$ Department of Anesthesiology, Faculty of Allied Medical Sciences, \\ Kerman University of Medical Sciences, Kerman, Iran \\ ${ }^{4}$ Department of Biostatistics and Epidemiology, Modeling in Health \\ Research Center, Institute for Futures Studies in Health, Kerman \\ University of Medical Sciences, Kerman, Iran
}

Yunes Jahani ${ }^{4}$ Katayoun Alidousti ${ }^{1}$ (1)

\author{
Address for correspondence Katayoun Alidousti, MSc in Midwifery, \\ Department of Midwifery, Razi School of Nursing and Midwifery, \\ Kerman University of Medical Sciences, Kerman, Iran \\ (e-mail: alidoosti@kmu.ac.ir).
}

Rev Bras Ginecol Obstet 2021;43(7):513-521.

\section{Abstract \\ Keywords \\ - functional analytical psychotherapy (FAP) \\ - cognitive behavioral therapy (CBT) \\ - sexual quality of life \\ - married women \\ - adolescents}

Objective Early marriage has many deleterious effects on the health of girls, such as sexual dissatisfaction, an inevitable result of the lack of sufficient knowledge about sexual issues at the time of the marriage. The goal of the present study was to determine the effectiveness of counseling based on functional analytic psychotherapy with enhanced cognitive therapy (FECT) on the sexual quality of life of married adolescent women.

Methods This clinical trial was conducted between July and October 2019 on 150 married adolescent women who met the inclusion criteria. In the intervention group, FECT was conducted in sixteen 90-minute sessions twice a week. The Sexual Quality of Life-Female (SQOL-F) questionnaire was used. When the study ended, the control group was given the choice of receiving the same intervention as the intervention group. Results The paired $t$-test showed a significant difference between the mean score of sexual quality of life before $(52.33 \pm 23.09)$ and after $(88.08 \pm 10.51)$ counseling in the intervention group $(p<0.0001)$. According to the analysis of covariance, there was a received

July 8,2020

accepted

April 22, 2021
DOI https://doi.org/

$10.1055 / \mathrm{s}-0041-1733914$ ISSN 0100-7203. (c) 2021. Federação Brasileira de Ginecologia e Obstetrícia. All rights reserved.

This is an open access article published by Thieme under the terms of the Creative Commons Attribution License, permitting unrestricted use, distribution, and reproduction so long as the original work is properly cited. (https://creativecommons.org/licenses/by/4.0/)

Thieme Revinter Publicações Ltda., Rua do Matoso 170, Rio de Janeiro, RJ, CEP 20270-135, Brazil 


\section{Resumo}

\section{Palavras-chave}

- psicoterapia analítica funcional (FAP)

- terapia cognitivocomportamental (TCC)

- qualidade de vida sexual

- mulheres casadas

- adolescentes significant difference between the score on sexual quality after counseling between the intervention $(88.08 \pm 10.51)$ and control $(60.32 \pm 23.73)$ groups $(p<0.0001)$. There was also a significant difference between the mean score on the four dimensions of sexual quality of life in the intervention group $(p<0.0001)$.

Conclusion The results showed that counseling based on FECT improved the sexual quality of life in all dimensions in married adolescent women.

Objetivo O casamento precoce tem muitos efeitos deletérios sobre a saúde das meninas, como a insatisfação sexual, resultado inevitável da falta de conhecimento suficiente sobre questões sexuais no momento do casamento. O objetivo do presente estudo foi determinar a eficácia do aconselhamento baseado em psicoterapia analítica funcional com terapia cognitiva aprimorada (FECT) na qualidade de vida sexual de mulheres adolescentes casadas.

Métodos Este ensaio clínico foi realizado entre julho e outubro de 2019 em 150 mulheres adolescentes casadas que preencheram os critérios de inclusão. No grupo de intervenção, FECT foi realizado em dezesseis sessões de 90 minutos duas vezes por semana. Foi utilizado o questionário Sexual Quality of Life-Female (SQOL-F). Quando o estudo terminou o grupo de controle teve a opção de receber a mesma intervenção do grupo de intervenção.

Resultados O teste t pareado mostrou diferença significativa entre o escore médio da qualidade de vida sexual antes $(52,33 \pm 23,09)$ e após $(88,08 \pm 10,51)$ o aconselhamento no grupo intervenção $(p<0,0001)$. De acordo com a análise de covariância houve diferença significativa entre o escore de qualidade sexual após aconselhamento entre os grupos intervenção $(88,08 \pm 10,51)$ e controle $(60,32 \pm 23,73)(p<0,0001)$. Também houve diferença significativa entre a pontuação média nas quatro dimensões da qualidade de vida sexual no grupo de intervenção $(p<0,0001)$.

Conclusão Os resultados mostraram que o aconselhamento baseado no FECT melhorou a qualidade de vida sexual em todas as dimensões em mulheres adolescentes casadas.

\section{Introduction}

Sexual activity is one of the most important aspects of human life. It can be influenced by personal characteristics, interpersonal relationships, the family, sociocultural conditions, the environment, the sexual-activity history of the individual and their spouse, physical and mental health, and the hormonal status of the individual. One of the most significant components of cohabitation is a healthy and satisfying sexual relationship between spouses, and having the necessary physical, mental, and social readiness is undoubtedly a necessity. ${ }^{1}$

Sexual compatibility is an important factor in happiness and good quality of life. ${ }^{2}$ Sexual relations can directly or indirectly affect the relationship of couples by affecting their thoughts and feelings. ${ }^{3}$ Sexual quality of life is an interactive and dynamic state that can change over time with changes in circumstances. An optimal sex life leads to more positive sexual feelings, which, in turn, result in happiness and satisfaction with life. ${ }^{4}$

The World Health Organization (WHO) defines the age range of 10 to 19 years as adolescence, which is one of the most important age groups in any society; therefeore, the health of adolescents is considered an important aspect of the health of society. ${ }^{5}$

The phenomenon of early marriage is increasing in Iranian society. Early marriage has many negative consequences on health, development, and the rights of children, especially of girls, and is often accompanied by the loss of educational opportunities, social isolation, exploitation, and physical, sexual and psychological violence by their husbands. ${ }^{6}$

Iranian cultural and religious backgrounds prevent open conversations about sexual relationships. ${ }^{7}$ Therefore, lack of sufficient knowledge about sexual issues causes these women to feel fear and disgust regarding having sex; this sexual dissatisfaction will definitely lead to coldness in the relationship with the husband. ${ }^{8}$

Studies $^{2,9}$ have shown that one-third of women do not enjoy sex with their partner, and almost one-fourth of them do not achieve orgasm. The prevalence of sexual dysfunction among American women ranges from $30 \%$ to $65 \%{ }^{10}$ The prevalence of these disorders is also reported to be of $69 \%$ in Egypt, ${ }^{11}$ and of $46.9 \%$ in Turkey. ${ }^{12}$ The rate of sexual 
dysfunction is reported to be of $21.9 \%$ among newly-married women in Sari, in Iran, ${ }^{13}$ and it has also been reported to be of $66 \%$ in newly-married women in Zanjan, also in Iran. ${ }^{13}$

Most couples seeking divorce in Iran were young age at the time of marriage, and this is considered the most common cause for divorce. Over $50 \%$ of the causes for divorce are sexual problems, which most often occur in the first 5 years of married life. ${ }^{8}$

Global studies show that around 82 million girls between the ages of 10 and 17 are getting married before the age of $18 ;{ }^{4}$ globally, 36\% of women between the ages of 20 and 24 are married before the age of 18 , with 14 million 15- to 19year-olds giving birth each year. ${ }^{8}$

In recent years, the highest number of marriages registered in Iran have involved men aged 20 to 24 and women aged 15 to 19; the number of recorded marriages of girls under 15 has dramatically increased in the past few years. ${ }^{14}$

Cognitive behavioral interventions have been used to improve the sexual quality of life in men and women, ${ }^{15}$ and studies ${ }^{16,17}$ have reported the effectiveness of functional analytical psychotherapy on self-esteem, anxiety, depression, quality of life, and marital satisfaction.

Functional analytic psychotherapy with enhanced cognitive therapy (FECT) relies on the skills, training, forms, procedures, and methods of cognitive therapy (CT), and, compared with standard CT, experienced cognitive therapists are interested in using this method. ${ }^{18}$

The two major enhancements FECT has brought to standard CT are the use of an expanded rationale for the causes and treatment of depression, and a greater use of the therapist-client relationship as an in-the-moment learning opportunity. In a preliminary, uncontrolled trial, ${ }^{19}$ FECT clients appreciated the expanded rationale, the incremental improvements in depression, and the major gains in interpersonal functioning.

Despite the fact that the level of literacy in Iran is relatively high, due to gaps in the health system, the issue of counseling in sex education has been greatly ignored. ${ }^{20}$ Considering the importance of adolescence and the high population of adolescent girls (5 million) in the country, and the fact that $17 \%$ of the country's marriages involve girls under 18 years of age, it may be possible to prevent some sexual problems in this age group. Therefore, the present study was conducted to determine the effect of the FECT approach on the sexual quality of life of married adolescent women.

\section{Methods}

The present clinical trial (code: IRCT2019021707042736N1) was conducted to determine the effect of FECT on the sexual quality of life of married adolescent women. Sampling was conducted for 3 months, from July to the end of October 2019. The sample consisted of 150 married adolescent women who met the inclusion criteria and were referred to health care centers in Darab, a city in the south of Shiraz province, Iran. The study power was of $80 \%$, and the significance level was 0.05 . The sample size was calculated to be 80 people ( 40 subjects in each group), but, due to probable dropouts, we increased it by $20 \%$.

Those who met the inclusion criteria were Iranian girls who were Darab residents, had a minimum level of literacy (reading and writing), were aged between 15 and 19 years, had been married for at least one year, had a monogamous husband (polygamy is an accepted practice in Muslim communities), had no extramarital relationships, were currently living with their husbands, had sex at least once a week, had not given birth in the previous year, reported that their spouses did not have any sexual issues, and had had an officially-registered marriage. ${ }^{9,21}$ The exclusion criteria were having an acute illness during the study, history of mental disorders during or before the study, experiencing a stressful incident during the month preceding the study, unwillingness to continue participating in the study, use of any psychiatric or psychotropic drugs, use of any psychological services, missing at least two counseling sessions, being pregnant, history of genital surgery, and addiction to drugs or alcohol. ${ }^{9,22}$

The eligible participants were randomly assigned to either the intervention or the control group at all eight of the health care centers in Darab. The names of the married teenagers were listed, and they were asked if they were willing to participate and if they met the inclusion criteria. A total of 150 girls met the inclusion criteria, and 75 were assigned to each group by drawing lots. Although the calculated sample size was smaller than this number, due to the large number of sessions, which increases the probability of dropouts, the study was conducted on all eligible individuals.

To facilitate the participants' commute due to the high number of counseling sessions, the intervention group was invited in groups of 10 to 12 people to the nearest health center to their residence to undergo counseling sessions. These participants completed the Sexual Quality of LifeFemale (SQOL-F) questionnaire and handed it in to the researcher before the start of the first counseling session and during sessions $2,4,6,8,10,12,14,15$, and 16 . Since each counseling session emphasized more on one aspect of the sexual quality of life, we asked the participants to fill out the questionnaire every couple of sessions to examine the differences in their answers. In the intervention group, FECT was conducted in sixteen 90-minute sessions twice a week.

The counseling sessions were based on the FECT method. To improve the efficacy of the sessions, cognitive techniques were applied to enhance the main domain of counselling (functional analytical psychotherapy, FAP). ${ }^{18,19}$ Homework was assigned to maintain the efficacy of the sessions during the intervention; it included the repetition of the techniques and making the requested behavioral changes at home, as well as concentration on the cognitive errors to replace them with correct behaviors (-Table 1). The pretest and posttest were performed for both study groups simultaneously. When the study ended, the control group was given the choice of receiving the same intervention as the other group. After the posttest, an educational pamphlet containing a summary of the content of the counseling sessions was provided to the control group. 
Table 1 Summary of the counseling sessions based on FECT

\begin{tabular}{ll}
\hline Session & Topic \\
\hline 1 & Introduction to the research variables
\end{tabular}

Content

Introduction, explanation of the goals and rules of the counseling sessions focusing on the sexual response cycle and the benefits of sex based on the FECT approach, and homework*

2 Introduction to the method and variables

Explanation of FECT-based counseling, its benefits and limitations, types of emotions, quality of life, and sexual self-efficacy, and homework

3 Sexual disorders and self-efficacy

Analytic interpretation of and cognitive approach to women's sexual disorders and related psychological problems, the impact of morality and law on sexual quality and self-efficacy, role play, and homework

4 Sexual role and confidence, clinically-relevant behavior

Analytic interpretation of and cognitive approach to sexual roles, physical sexual attraction, sexual confidence, working on clients' clinically-relevant behavior through role play, and homework

$5 \quad$ Gender identity, clinically-relevant behavior

Cognitive errors about gender identity and the factors affecting it, working on the arousal of clinically-relevant behavior through role play, and homework

6 Sexual orientation, clinically-relevant behavior

Gender and sexual orientation, working on strengthening clinically-relevant behavior through role play, and homework

$7 \quad$ Communication skills and addiction

Working on effective marital-communication skills, behaviors that lead to sexual self-efficacy, the impact of various types of addiction on sexual relations, and homework

8 Sex life of men (husbands accompanied their wives in this session)

Cognitive focus on sexual quality of life and sexual disorders among men, and homework

9 Sexual goals

10 Sexual satisfaction

Analytic interpretation and cognitive approach to general and sexual self-efficacy and factors affecting it (such as sexual goals, self-confidence, self-esteem), and homework

Analytic interpretation and cognitive approach to sexual feelings, marital and sexual satisfaction, and their influencing factors, and homework

$11 \quad$ Femininity

Analytic interpretation of femininity and cognitive approach to the difference between dependence and love, how valuable women are (femininity, sexual confidence, the sense of guilt in sex life), and homework

12 Cultural factors

Analytic interpretation and cognitive approach to the cognitive triangle, sexual repression (feelings of pleasure, culture-related sexual errors), and homework

13 Improvement in sex life

Analytic interpretation of and cognitive approach to sexual competence, dealing with unexpected issues in sex life, ways to create variety in sex life, and homework

14 Role play

Interpretation of variables affecting behavior through role play, and homework

$15 \quad$ Review

16 Review

Review session, review of practical techniques, and homework

Review session, review of practical techniques

Abbreviation: FECT, functional analytic psychotherapy with enhanced cognitive therapy.

Source: Khajeh et al. ${ }^{15}$ and Kanter et al. ${ }^{23}$

Note: *Homework: practicing mindfulness-based changes in thoughts, emotions, and behaviors related to sexual life.

To achieve the research objectives, two questionnaires were used: a demographic questionnaire and the SQOL-F. The demographic questionnaire collected data on gender, age, duration of marriage, spouse's age, self-employment, spouse's job, number of children, level of schooling etc.

The SQOL-F was first evaluated by Symonds et al. ${ }^{24}$ in 2005 in the United Kingdom and the United States. The internal consistency was of 0.95 , and the intragroup correlation coefficient was of 0.85 . The questionnaire consists of 18 questions graded on the Likert scale; each question is graded from 0 to $100(0-20-40-60-80-100)$. The total score of the questionnaire is between 0 and 100 . Questions $1,5,9,13$, and 18 are reverse-scored. The criterion for interpretation is the average score of the research population, which means that a score lower than the average of the research population indicates poor sexual quality of life, and a score higher than the average of the research population indicates the desired sexual quality of life. ${ }^{25}$ 
For the statistical analysis, we used the Statistical Package for the Social Sciences (IBM SPSS Statistics for Windows, IBM Corp., Armonk, NY, US) software, version 24. As we had repetitions in the measurement, we used repeated measures analysis of variance (ANOVA) to make comparisons within the intervention group. To compare the intervention and control groups after the intervention, we used analysis of covariance (ANCOVA). The independent samples $t$-test was used to compare the study groups before the intervention due to the normality of the data, and the Chi-squared test was used to examine the similarity between both groups. The paired $t$-test was used to compare the groups before and after the intervention. To observe ethical considerations, in addition to obtaining written informed consent from the participants, the study was conducted under ethical code IR.KMU. REC.1398.091, issued by the Ethics Committee at Kerman University of Medical Sciences, and clinical trial code IRCT2019021707042736N1, issued by the Iranian Registry of Clinical Trials.

\section{Results}

In the present study, 150 married teenage women, divided into 2 groups of 75 each, were examined, and 50 (25 women in each group) were excluded from the study. The reasons for exclusion from the intervention group were: starting school and having preparation classes for university entrance exams (ten participants); university admission and moving to another city (nine participants); pregnancy (two participants); and unwillingness to attend the meetings (one participant); in addition, three women dropped out of the study due to concomitant use of antidepressants. In the control group, some members were excluded due to failure to complete the posttest questionnaire (19 participants), or because they sent an empty questionnaire (6 participants). The pretest and posttest were competed by both study groups simultaneously. Finally, the data on 50 women in each group were analyzed.

According to the results shown in - Table 2, the mean age of the participants was $17.62 \pm 1.32$ years (intervention group) and $17.38 \pm 1.15$ years (control group) $(p=0.33$ ) The mean age of the spouse was $27.56 \pm 3.43$ years and $26.56 \pm 3.02$ years in the intervention and control groups respectively $(p=0.12)$. There was a significant difference between the groups in terms of the number of children $(p=0.04)$, but there was no significant difference between them regarding level of schooling, spouse's level of schooling, or spouse's job.

There was no significant difference between the mean score on sexual quality of life before counseling in the intervention $(52.33 \pm 23.09)$ and control $(59.57 \pm 22.12)$ groups $(p=0.11)$, that is, the groups were not significantly different in terms of sexual quality of life before the intervention. There was a significant difference between the mean score on sexual quality of life before $(52.33 \pm 23.09)$ and after $(88.08 \pm 10.51)$ counseling in the intervention group $(p<0.0001)$. However, in regard to this, there was no significant difference in the control group $(p=0.30)$. There was a

Table 2 Demographics of the study groups

\begin{tabular}{|c|c|c|c|c|}
\hline Variable & Intervention group: $\mathrm{N}(\%)$ & Control group $\mathrm{N}(\%)$ & Chi-squared test & $p$-value \\
\hline Women education level: & & & 0.31 & 0.85 \\
\hline First high school & $7(14)$ & $6(12)$ & & \\
\hline Second high school & $35(70)$ & $34(68)$ & & \\
\hline Diploma and higher education & $8(16)$ & $10(20)$ & & \\
\hline Husband's level of schooling: & & & 2.78 & 0.59 \\
\hline Illiterate & $2(4)$ & $0(0)$ & & \\
\hline Elementary & $6(12)$ & $4(8)$ & & \\
\hline Diploma & $20(40)$ & $20(40)$ & & \\
\hline Associate degree & $10(20)$ & $11(22)$ & & \\
\hline Bachelors & $12(24)$ & 15(30) & & \\
\hline Husbandś education level: & & & 0.60 & 0.89 \\
\hline Unemployed & $5(10)$ & $3(6)$ & & \\
\hline Worker & $5(10)$ & $6(12)$ & & \\
\hline Freelancer & $30(60)$ & $31(62)$ & & \\
\hline Employed & $10(20)$ & $10(20)$ & & \\
\hline Number of children & & & & 0.04 \\
\hline 0 & $27(54)$ & $27(54)$ & - & \\
\hline 1 & $15(30)$ & $15(30)$ & - & \\
\hline 2 & $7(14)$ & $7(14)$ & - & \\
\hline 3 & $1(2)$ & $1(2)$ & - & \\
\hline
\end{tabular}


Table 3 Comparison of the mean score on sexual quality of life and its dimensions before and after counseling in both groups

\begin{tabular}{|c|c|c|c|c|}
\hline Variable & Group & $\begin{array}{l}\text { Before counseling: } \\
\text { mean } \pm \text { standard } \\
\text { deviation }\end{array}$ & $\begin{array}{l}\text { After counseling: } \\
\text { mean } \pm \text { standard } \\
\text { deviation }\end{array}$ & $p$-value \\
\hline \multirow[t]{2}{*}{ Sexual psychology } & Intervention & $50 \pm 25.64$ & $84.62 \pm 12.68$ & $<0.0001$ \\
\hline & Control & $58.20 \pm 23.31$ & $59.06 \pm 25.10$ & 0.414 \\
\hline \multirow[t]{2}{*}{ Sexual satisfaction } & Intervention & $57.68 \pm 24.05$ & $93.84 \pm 8.20$ & $<0.0001$ \\
\hline & Control & $64.12 \pm 21.94$ & $64.79 \pm 23.53$ & 0.542 \\
\hline \multirow[t]{2}{*}{ Sexual self- humiliation } & Intervention & $49.20 \pm 24.86$ & $87.73 \pm 12.07$ & $<0.0001$ \\
\hline & Control & $59.46 \pm 25.97$ & $59.33 \pm 27.80$ & 0.909 \\
\hline \multirow[t]{2}{*}{ Sexual repression } & Intervention & $52 \pm 22.77$ & $86.93 \pm 13.46$ & $<0.0001$ \\
\hline & Control & $55.33 \pm 23.26$ & $56.80 \pm 24.77$ & 0.219 \\
\hline \multirow{2}{*}{$\begin{array}{l}\text { Total sexual } \\
\text { quality of life }\end{array}$} & Intervention & $52.33 \pm 23.09$ & $88.08 \pm 10.51$ & $<0.0001$ \\
\hline & Control & $59.57 \pm 22.12$ & $60.32 \pm 23.73$ & 0.39 \\
\hline
\end{tabular}

significant difference between the mean score in the 4 dimensions of sexual quality of life: psychosexual aspects $(84.62 \pm 12.68)$, sexual satisfaction $(93.84 \pm 8.20)$, sexual self-humiliation $(87.73 \pm 12.07)$, and sexual repression $(86.93 \pm 13.46)$ after counseling within the intervention group ( $p<0.0001)$. However, there was no such difference in the control group ( - Table 3 ). According to the ANCOVA, there was a significant difference between the score on sexual quality of life after counseling between the intervention $(88.08 \pm 10.51)$ and control $(60.32 \pm 23.73)$ groups $(p<0.0001)$, with an average score of 31.91 (95\% confidence interval [95\%CI]: 27.89-35.92) in the intervention group after counseling.

As can be seen from the repeated measures ANOVA, there was a significant difference between the average sexual quality of life and its dimensions at different times $(p<0.0001)$ (-Table 4). The mean score increased over time in the intervention group. An elevation was observed in the mean score of different dimensions in different sessions. In the

Table 4 Trend of the average score on sexual quality of life during counseling sessions in the intervention group

\begin{tabular}{llll}
\hline Group & Intervention & & \\
\hline $\begin{array}{l}\text { Sexual quality } \\
\text { of life }\end{array}$ & $\begin{array}{l}\text { Mean } \pm \text { standard } \\
\text { deviation }\end{array}$ & $F$ & p-value* \\
\hline F-test & $52.33 \pm 23.09$ & 189.27 & $<0.0001$ \\
Session 2 & $60.02 \pm 22.89$ & & \\
Session 4 & $64.97 \pm 21.68$ & & \\
Session 6 & $69.02 \pm 20.05$ & & \\
Session 8 & $72.04 \pm 18.13$ & & \\
Session 10 & $77.64 \pm 15.56$ & & \\
Session 12 & $81.88 \pm 13.54$ & & \\
Session 14 & $84.57 \pm 12.10$ & \\
Session 16 & $88.08 \pm 10.51$ & \\
\hline
\end{tabular}

Note:* Repeated measures analysis of variance (ANOVA).

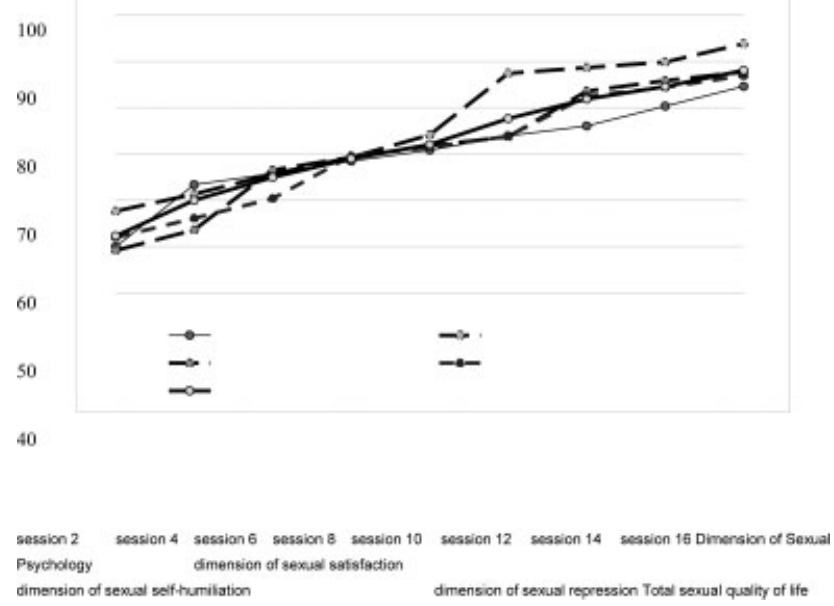

Fig. 1 Changes in sexual quality of life and its dimensions during counseling sessions in the intervention group.

second and twelfth sessions, the psychological dimension improved; in the eighth session, the sexual dimension improved; sexual humiliation improved in the second and tenth sessions; and the sexual repression subscale improved in the fourth and tenth sessions (-Fig. 1).

\section{Discussion}

The present study was conducted to determine the effect of FECT on the sexual quality of life of married adolescent women. The results show a significant difference regarding the mean score on sexual quality of life of both study groups $(p<0.0001)$. A significant difference in the score on sexual quality of life after counseling was also observed for both groups through the ANCOVA $(p<0.0001)$. This shows that FECT was effective in improving the sexual quality of life, which is consistent with the results found by Fatehi et al. ${ }^{25}$ on the effect of psychological counseling on sexual quality of life and sexual function among breast cancer survivors in Iran. ${ }^{25}$ Similar to the present study, the meta-analysis emphasized that individual and group psychological interventions using 
the cognitive approach and multidimensional therapies with long term follow-ups are suggested for the treatment of sexual dysfunction and for sexual life. ${ }^{26}$ Another research ${ }^{27}$ also showed that sexual rehabilitation programs have positive effects on the sexuality of patients undergoing hemodialysis. These similarities could be due to the use of psychotherapeutic interventions and counseling. Sexual rehabilitation programs, as well as FECT, increase self-esteem and the participants' ability to resume their lives as sexual beings, as their acceptance of their sexuality is addressed in rehabilitation. Furthermore, the participants' ability to resume their lives as sexual beings was affected by the their own attitudes, and those of their partners and of society. Etemadi et al. ${ }^{28}$ conducted conducted a study with the aim of determining the effect of FAP on the rates of depression, anxiety, and marital satisfaction of women with marital issues. The results showed that FAP was effective in reducing depression and anxiety and increasing marital satisfaction. ${ }^{28}$ The present research aimed at increasing the effectiveness of FAP by adding a cognitive element to the counselling sessions.

The results showed that there was a significant difference between the mean score on sexual quality of life before and after counseling in the intervention group $(p<0.0001)$, that is, counseling was able to improve the sexual quality of life of the research participants. Alimohammadi et al. ${ }^{29}$ conducted a clinical trial with a sample of 96 newly-married women with the aim of investigating the effect of counseling based on Bandura's self-efficacy theory on sexual self-efficacy and sexual quality of life. The intervention was performed in the form of six 90-minute sessions per week, and the results showed that counseling improved sexual self-efficacy, but did not affect the sexual quality of life. It seems that counseling based on Bandura's self-efficacy theory cannot cover all dimensions of sexual quality of life.

Abdelhakm et al. ${ }^{30}$ reported that the permission, limited information, specific suggestions, and intensive therapy (PLISSIT) model sexual counseling program has a significant effect on improving the sexual quality of life of women in the postpartum period. The PLISSIT enables participants to freely discuss sexual issues in order to solve sexual problems and enhance sexual quality of life. With the FECT, these two aims are achieved by working on clinically-relevant behavior (CRB) and modifying cognitive errors and behavioral problems in sexual life to produce positive changes in those behaviors. ${ }^{18}$

According to the results of the present study, there was a significant difference in the mean score on the four dimensions (psychosexual aspects, sexual satisfaction, sexual selfhumiliation, and sexual repression) of sexual quality of life before and after counseling in the intervention group $(p<0.0001)$. In addition, the repeated measures ANOVA showed that there was a significant difference in the average sexual quality of life and its dimensions at different times $(p<0.0001)$. In the present study, FECT was able to have a positive effect on all aspects of sexual quality of life. Also, progress was examined in each session, and clear progress in each dimension was observed in specific sessions according to the content of that day. Ahmadian et al. ${ }^{31}$ also obtained similar results by examining the problem-solving sexual therapy process of couples with sexual issues, demonstrating that the couples made progress in each session. Teaching problem-solving as a component of emotional intelligence was effective on enhancing sexual quality of life. ${ }^{32}$ Both cognitive behavioral therapy (CBT) and problem-solving therapy indicated significant improvements in satisfaction over time. $^{33}$

The 2013 study by Steinke et al. ${ }^{34}$ aimed to determine the effect of comprehensive sexual counseling based on social cognitive theory on the dimensions of sexual satisfaction, sexual self-efficacy, awareness, return to sexual activity, sexual anxiety, sexual depression, and quality of life. The study was performed on heart attack patients aged $\geq 45$ years and their spouses. Educational videos, telephone counseling, and pamphlets were used in the intervention. The study was conducted on 10 patients and on the sexual partners of 3 of them. Eight weeks after the intervention, the findings showed that the participants' knowledge and information had increased. Sexual self-efficacy before and after the intervention was similar, and there was no significant difference in terms of sexual anxiety before and after the intervention. ${ }^{34}$

This may be related to the fact that social cognitive theory (SCT) does not provide a full explanation or description of how social cognition, behavior, environment, and personality are related. ${ }^{35}$

One study ${ }^{21}$ showed that four 90-minute sessions of educational intervention did not cause a significant change in a woman's sense of guilt from coitus during pregnancy, of the immorality of coitus during pregnancy, and of the dislike for her pregnant appearance from the point of view of the spouse. Educational intervention, by focusing on information about psychological and physiological changes that occur during the sexual response, may not be as effective as FECT. ${ }^{26}$

Health is one of the basic human rights, and adolescent health is a priority in most societies. There is little research on adolescent sexual problems, but evidence suggests that these problems cause concern and distress among adolescents. $^{22}$ Young people are usually less aware of sexual issues, which increases their sexual problems, and, as a result, their anxiety and worry; thus, this may create a wide range of misconceptions and false beliefs. Empowering young people by increasing their awareness regarding sexual issues can encourage them to seek professional help. ${ }^{36}$ The high number of sessions was one of the limitations of the present research; however, the results can be used in the field of clinical and counseling services to enrich the knowledge and skills of adolescents and increase their ability to express their issues in this field.

\section{Conclusion}

The results showed that FECT improved sexual quality of life among married adolescent women.

Contributions

MG and KA designed the study and drafted the manuscript. AA prepared the counselling package. MT had full access to all of the data and was in charge of the integrity of the data. 
YJ was responsible for the accuracy of the data analysis. All authors read and approved the final manuscript.

\section{Conflict of Interests}

The authors have no conflict of interests to declare.

\section{Acknowledgments}

We would like to thank the research deputy of Kerman University of Medical Sciences, all the staff at the health care center, as well as the teenage women who participated in this research.

\section{References}

1 Nezal AJ, Rad FS, Kalhor M, Hasanpour K, Alipour M, Montazeri A. Sexual quality of life in pregnant women: a cross sectional study. Payesh. 2018;17(04):421-429

2 Mofid V, Ahmadi A, Etemadi O. The comparison of cognitivebehavioral counseling and solution-oriented counseling on women's sexual satisfaction in Isfahan. J Woman Soc.. 2014;5(03): 67-83

3 Ebrahimipour H, Jalambadany Z, Peyman N, Ismaili H, Vafaii Najjar A. Effect of sex education, based on the theory of planned behavior, on the sexual function of the woman attending Mashhad health centers. J Birjand Univ Med Sci.. 2013;20(01):58-67

4 Reissing ED, Laliberté GM, Davis HJ. Young women's sexual adjustment: the role of sexual self-schema, sexual self-efficacy, sexual aversion and body attitudes. Can J Hum Sex. 2005;14(3-4):77-85

5 Breuner CC, Mattson GCOMMITTEE ON ADOLESCENCE COMMITTEE ON PSYCHOSOCIAL ASPECTS OF CHILD AND FAMILY HEALTH. Sexuality Education for Children and Adolescents. Pediatrics. 2016;138(02):e2-11. Doi: 10.1542/peds.2016-1348

6 Meghdadi MM, Javadpour M. Impact of early marriage on children's sexual health and mechanisms of deal with it. Med Law J.. 2017;11(40):31-60

7 Hosseininasab A, Alidoosti K, Forouhari S. Health-related counseling needs in adolescent girls: a qualitative study. Health Scope. 2016;5(02):e2-16. Doi: 10.17795/jhealthscope-24601

8 Samimi K, Mokarami H, Tontab Haghighi S, Taban E, Yazdani Aval M, Maasoumi R. Assessment of affecting factors on women's sexual quality of life among hospital employees. Majallah-i Danishgah-i Ulum-i Pizishki-i Gurgan. 2016;18(03):128-134

9 Zare Z, Golmakani N, Khadem N, Shareh H, Shakeri M. The effect of pelvic floor muscle exercises on sexual quality of life and marital satisfaction in primiparous women after childbirth. Majallah-i Zanan, Mamai va Nazai-i Iran. 2014;17(103):21-32. Doi: 10.22038/ijogi.2014.3007

10 Lamyian M, Zarei F, Montazeri A, Hajizadeh E, Maasoumi R. Exploring the factors affecting Iranian women's quality of sexual life. J Hayat.. 2016;22(02):185-200

11 Elnashar AM, El-Dien Ibrahim M, El-Desoky MM, Ali OM El-Sayd Mohamed Hassan M. Female sexual dysfunction in Lower Egypt. BJOG. 2007;114(02):201-206. Doi: 10.1111/j.14710528.2006.01106.X

12 Cayan S, Akbay E, Bozlu M, Canpolat B, Acar D, Ulusoy E. The prevalence of female sexual dysfunction and potential risk factors that may impair sexual function in Turkish women. Urol Int. 2004; 72(01):52-57. Doi: 10.1159/000075273

13 Alimohammadi L, Zarei F, Mirghafourvand M. Factors associated with sexual dysfunction in newly married women referred to the urban health centers of Zanjan, Iran: a cross-sectional study. Int J Women's Health Reprod Sci. 2018;6(04):477-482. Doi: 10.15296/ ijwhr.2018.79

14 Mae Delara RR, Cottrell C, Savitski J. Effects of adverse childhood experiences on female sexual quality of life. Obstet Gynecol. 2018; 131(Suppl):146S-151S
15 Khajeh A, Bahrami F, Fatehizadeh M, Abedi M, Sajjadian P. The effect of happiness training based on cognitive behavioral approach on quality of marital life in married males and females. Knowledge Res Appl Psychol.. 2013;14(03):11-21

16 Mirenayat P, Abedi M, Izadi R. Effect of Functional Analytic Psychotherapy (FAP) on self-esteem of prostitutes: singlesubject design. Knowledge Res Appl Psychol.. 2017;18(02): 22-36

17 Etemadi A, Gholizadeh H, Salimi H, Farahbakhsh K. The comparison of the effectiveness of functional analytic psychotherapy with unified protocol for trans diagnostic treatment on depression, anxiety and marital satisfaction among women with marital distress. Thoughts Behav Clin Psychol.. 2017;12(46): 47-56

18 Kanter JW, Manbeck KE, Kuczynski AM, Maitland DWM, VillasBôas A, Reyes Ortega MA. A comprehensive review of research on Functional Analytic Psychotherapy. Clin Psychol Rev. 2017; 58:141-156. Doi: 10.1016/j.cpr.2017.09.010

19 Kohlenberg RJ, Kanter JW, Bolling M, Wexner R, Parker C, Tsai M. Functional analytic psychotherapy, cognitive therapy, and acceptance. In: Hayes SC, Follette VM, Linehan MM, editors. Mindfulness and acceptance: expanding the cognitive-behavioral tradition. New York: Guilford; 2004:96-119

20 Reihani Asl F, Khayatan F. The effectiveness of sex education on women sexual schemas, women sexual self-esteem and sexual satisfaction in women who refer to counseling's centers of esfahan. Nurs Midwifery J.. 2018;16(02):130-138

21 Mohamadi S, Ozgoli G, Alizadeh S, Borumandnia N, Abbas A. The effect of modification of dysfunctional sexual beliefs on promotion of quality of pregnant women sexual life in Besat hospital. Resen Med. 2017;41(03):166-174

22 Haberland N, Rogow D. Sexuality education: emerging trends in evidence and practice. J Adolesc Health. 2015;56(1, Suppl): S15-S21. Doi: 10.1016/j.jadohealth.2014.08.013

23 Kanter JW, Tsai M, Kohlenberg RJ. Introduction to the practice of functional analytic psychotherapy. In: Kanter JW, Tsai M, Kohlenberg RJ, eds. The practice of functional analytic psychotherapy. New York: Springer; 2010:1-7

24 Symonds T, Boolell M, Quirk F. Development of a questionnaire on sexual quality of life in women. J Sex Marital Ther. 2005;31(05): 385-397. Doi: 10.1080/00926230591006502

25 Fatehi S, Maasoumi R, Atashsokhan G, Hamidzadeh A, Janbabaei $G$, Mirrezaie SM. The effects of psychosexual counseling on sexual quality of life and function in Iranian breast cancer survivors: a randomized controlled trial. Breast Cancer Res Treat. 2019;175 (01):171-179. Doi: 10.1007/s10549-019-05140-z

26 Kharaghani R, Esm Khani M, Mahmoodi Dangesaraki M, Damghanian $M$. The effects of psychological interventions on sexual function of women: a systematic review and meta-analysis. NPT. 2020;7(03):169-182. Doi: 10.18502/npt.v7i3.3345

27 Alvandi Jam A, Afshari A, Talebi M, Abasi R. The effect of sexual rehabilitation on (Sexual) quality of life for hemodialysis patients referred to dialysis center in Labafinejad Hospital. Avicenna J Nurs Midwifery Care.. 2015;22(04):45-52

28 Etemadi A, Salimi H, Farahbakhsh K, Gholizadeh H. The efficacy functional anaiytic psychotherapy depression, anxiety symptoms and martial satisfaction among women with martial distress. QJ Mod Psychol Res.. 2018;13(49):1-20

29 Alimohammadi L, Zarei F, Mirghafourvand M. The effect of counseling based on Bandura's self-efficacy theory on sexual self-efficacy and quality of sexual life. Women Health. 2020;60 (04):473-486. Doi: 10.1080/03630242.2019.1662871

30 Abdelhakm EM, Said AR, Elsayed DMS. Effect of PLISSIT model sexual counseling program on quality of sexual life for postpartum women. Am J Nurs Sci. 2018;7(02):63-72. Doi: 10.11648/j. ajns.20180702.14

31 Ahmadian AR, Hatami M, Tajik AA, Zahrakar K, Hasani J. The effectiveness of problem-solving oriented sex therapy based on 
the Islamic approach for couple's sexual problems (Feasibility study, compilation of conceptual model and initial therapeutic outcomes). Womens Stud. 2018;9(01):37-71

32 Milani AS, Hosseini M, Matbouei M, Nasiri M. Effectiveness of emotional intelligence training program on marital satisfaction, sexual quality of life, and psychological well-being of women. J Educ Health Promot. 2020;9:149. Doi: 10.4103/jehp.jehp_124_20

33 Stewart CD, Quinn A, Plever S, Emmerson B. Comparing cognitive behavior therapy, problem solving therapy, and treatment as usual in a high risk population. Suicide Life Threat Behav. 2009; 39(05):538-547. Doi: 10.1521/suli.2009.39.5.538
34 Steinke EE, Mosack V, Hertzog J, Wright DW. A social-cognitive sexual counseling intervention post-MI-development and pilot testing. Perspect Psychiatr Care. 2013;49(03):162-170. Doi: 10.1111/j.1744-6163.2012.00345.x

35 Sincero SM. Social cognitive theories of personality [Internet]. 2012 [cited 2020 Aug 27]. Available from: https://explorable.com/ social-cognitive-theories-of-personality

36 O'Sullivan LF, Brotto LA, Byers ES, Majerovich JA, Wuest JA. Prevalence and characteristics of sexual functioning among sexually experienced middle to late adolescents. J Sex Med. 2014;11 (03):630-641. Doi: 10.1111/jsm.12419 